\title{
Identifying the Potential Differentially Expressed miRNAs and mRNAs in Osteonecrosis of the Femoral Head Based on Integrated Analysis
}

This article was published in the following Dove Press journal:

Clinical Interventions in Aging

\section{Yangquan Hao \\ Chao Lu \\ Baogang Zhang \\ Zhaochen Xu \\ Hao Guo \\ Gaokui Zhang}

Department of Osteonecrosis and Joint Reconstruction, Honghui Hospital Xian Jiao Tong University Health Science Center, Xian, Shaanxi 710068, People's Republic of China
Correspondence: Yangquan Hao Department of Osteonecrosis and Joint Reconstruction, Honghui Hospital Xian Jiao Tong University Health Science Center, No. 555 Youyi East Road, Xian, Shaanxi 710068, People's Republic of China

Tel +86 I3991038599

$\mathrm{Fax}+86$ 29-87894724

Email yangquan_haodoctor@163.com
Purpose: Osteonecrosis of the femoral head is a common disease of the hip that leads to severe pain or joint disability. We aimed to identify potential differentially expressed miRNAs and mRNAs in osteonecrosis of the femoral head.

Methods: The data of miRNA and mRNA were firstly downloaded from the database. Secondly, the regulatory network of miRNAs-mRNAs was constructed, followed by function annotation of mRNAs. Thirdly, an in vitro experiment was applied to validate the expression of miRNAs and targeted mRNAs. Finally, GSE123568 dataset was used for electronic validation and diagnostic analysis of targeted mRNAs.

Results: Several regulatory interaction pairs between miRNA and mRNAs were identified, such as hsa-miR-378c-WNT3A/DACT1/CSF1, hsa-let-7a-5p-RCAN2/IL9R, hsa-miR-28-5pRELA, hsa-miR-3200-5p-RELN, and hsa-miR-532-5p-CLDN18/CLDN10. Interestingly, CLDN10, CLDN18, CSF1, DACT1, IL9R, RCAN2, RELN, and WNT3A had the diagnostic value for osteonecrosis of the femoral head. Wnt signaling pathway (involved WNT3A), chemokine signaling pathway (involved RELA), focal adhesion and ECM-receptor interaction (involved RELN), cell adhesion molecules (CAMs) (involved CLDN18 and CLDN10), cytokine-cytokine receptor interaction, and hematopoietic cell lineage (involved CSF1 and IL9R) were identified.

Conclusion: The identified differentially expressed miRNAs and mRNAs may be involved in the pathology of osteonecrosis of the femoral head.

Keywords: osteonecrosis of the femoral head, miRNAs, mRNAs, signaling pathway

\section{Introduction}

Osteonecrosis of the femoral head is a disabling and progressive chronic disease, which leads to femoral head collapse and further total hip arthroplasty. ${ }^{1,2}$ It is estimated that the age range of about $75 \%$ of patients is from $30-60$ years old. ${ }^{3}$ Pain is one of the common clinical symptoms of osteonecrosis of the femoral head. ${ }^{4}$ However, most patients with a lesion less than $30 \%$ of the femoral head are initially asymptomatic. $^{5}$ Malizos $^{6,7}$ and Zalavras and Lieberman found that osteocytes death and bone marrow cells was the main characteristic of the early stages of osteonecrosis of the femoral head. In the next moment, the repair reaction of necrotic bone is initiated. During this process, the imbalance between bone resorption and bone reformation leads to structural damage of the femoral head, among which there is a significant degeneration and cracking of the hip articular cartilage, which accelerates the development of osteonecrosis of the femoral head. ${ }^{8,9}$ 
The pathogenic mechanism of osteonecrosis of the femoral head is complex. Kerachian et $\mathrm{al}^{10}$ found that local microvascular thrombosis resulted in decreasing blood flow in the femoral head. It was pointed out that fibroblast growth factor 2 (FGF2), insulin-like growth factor 1 (IGF1), SRY-box transcription factor 9 (SoX9), and collagen type ii $\alpha 1$ affected the pathogenesis of osteonecrosis of the femoral head. ${ }^{11}$ In addition, several risks, such as the trauma, steroids, smoking, alcoholism, irradiation/chemotherapy, clotting disturbances, hyperlipidemia, hyperviscosity, autoimmune diseases, Legg-Calve-Perthes diseases, and genetic factors are possible causes of osteonecrosis of the femoral head. ${ }^{12-22}$

The incidence of osteonecrosis of the femoral head is on the rise, in spite of various research efforts and trials. Therefore, understanding the pathophysiology of the disease and its progression is urgently needed. Interestingly, miRNAs play roles in targeting mRNAs, and regulate diverse biological processes in bones, such as osteoblasts, osteoclasts differentiation, and bone programming. ${ }^{23-26}$ In this study, we performed the differentially expression analysis of miRNA and mRNA in osteonecrosis of the femoral head, which may provide a novel field in understanding the pathological mechanism of osteonecrosis of the femoral head.

\section{Materials and Methods}

\section{Datasets}

The miRNA and mRNA expression profile was downloaded from the Gene Expression Omnibus database (GEO) dataset. The keywords of (("femur head" [MeSH Terms] OR femoral head [All Fields]) AND ("necrosis" [MeSH Terms] OR necrosis [All Fields])) AND "gse" [Filter] was used to retrieve related datasets. According to above screening criteria, one miRNA dataset (GSE89587, involving ten cases and seven normal controls) and one mRNA dataset (GSE74089, involving four cases and four normal controls) were finally selected.

\section{Identification of Differentially Expressed miRNAs and mRNAs}

Firstly, the raw data of miRNAs and mRNAs was preprocessed as follows: the probes corresponding to multiple miRNAs/mRNAs were removed; and the miRNAs/ mRNAs corresponding to multiple probes were left with only the one with the highest average expression. In this study, the identification method of differentially expressed miRNAs and mRNAs was referred to previous studies. $^{27,28}$ The screening criteria of differentially expressed miRNAs and mRNAs was, respectively, $\mathrm{FDR}<0.05,|\log 2 \mathrm{FC}|>3$, and $\mathrm{FDR}<0.05,|\log 2 \mathrm{FC}|>1$.

\section{Correlation Analysis Between miRNAs and mRNAs}

In this study, miRWalk (http://mirwalk.umm.uniheidelberg.de/) was used to predict targeted mRNAs of miRNAs. The establishment of a miRNA-target regulatory network was visualized using Cytoscape software.

\section{Functional Enrichment of mRNAs}

In order to understand the biological function of the targeted differentially expressed mRNAs of differentially expressed miRNAs, we performed functional analysis via GeneCodis3 software. FDR $<0.05$ was set as the criterion for selecting significantly enriched functional terms.

\section{In vitro Validation of miRNAs and Targeted mRNAs}

In total, six patients with osteonecrosis of the femoral head and seven normal controls were enrolled. All patients had not taken corticosteroids or medications for nearly a month. In addition, patients older than 80 years or without incomplete clinical information were excluded. Normal controls were matched by gender and age of the case group. Healthy individuals with a history of osteonecrosis of the femoral head and suffering from bone metabolic disorders (such as osteoporosis) were excluded. Ethical approval was obtained from the ethics committee of Honghui Hospital Xian Jiao Tong University Health Science Center (No.201904006). Those included provided informed written consent. This study was carried out in accordance with the Declaration of Helsinki.

Total RNA of the blood samples was extracted and synthesized cDNA by FastQuant Reverse Transcriptase (TIANGEN). Then real-time PCR was performed in an ABI 7300 Real-time PCR system with SYBR ${ }^{\circledR}$ Green PCR Master Mix (Applied Biosystems). Has-U6 was used for the internal reference of miRNA. ACTB and GAPDH were used for the internal reference of mRNA.

\section{Electronic Validation and Diagnostic Analysis of Targeted mRNAs in GSEI 23568 Dataset}

The GSE123568 dataset (peripheral blood sample) involved 30 patients with osteonecrosis of the femoral head and 10 
normal controls, and was used for electronic validation and ROC analysis of targeted mRNAs. The expression result of these mRNAs was shown by box plots.

\section{Results}

\section{Expression Pattern of miRNA and mRNA}

There were 24 differentially expressed miRNAs (supplementary Table 1), and 901 differentially expressed mRNAs (supplementary Table 2) were identified. All differentially expressed miRNAs and the top 20 differentially expressed mRNAs are shown in Tables 1 and 2, respectively. The volcano plot and heat map of all miRNAs and top 100 mRNAs are shown in Figures 1 and 2 , respectively.

\section{Network of miRNAs-mRNAs}

Depending on the targeted analysis, 2,137 miRNA-mRNA pairs (involving 24 miRNA and 457 mRNA) were identified (supplementary Table 3). The established regulatory network of miRNA-targeted mRNA is illustrated in Figure 3. In the network, there were 481 nodes and

Table I All Differentially Expressed miRNAs in Osteonecrosis of the Femoral Head

\begin{tabular}{|c|c|c|c|c|}
\hline Symbol & LogFC & P-value & FDR & Up/Down \\
\hline hsa-miR-3|9|-5p & -3.15065 & $3.62 \mathrm{E}-07$ & 0.000358 & Down \\
\hline hsa-miR-45I I & -4.24635 & $5.12 \mathrm{E}-06$ & 0.000514 & Down \\
\hline hsa-miR-5 I95-5p & -3.1202 & $5.88 \mathrm{E}-06$ & 0.000514 & Down \\
\hline hsa-miR-I28-3p & 3.473807 & $7.27 \mathrm{E}-06$ & 0.000514 & Up \\
\hline hsa-miR-374c-5p & 3.70425 & I.30E-05 & 0.000722 & Up \\
\hline hsa-miR-532-5p & 3.811221 & 2.07E-05 & 0.000764 & $U_{p}$ \\
\hline hsa-miR-I40-5p & 3.711132 & $2.09 \mathrm{E}-05$ & 0.000764 & Up \\
\hline hsa-miR-3200-3p & 3.396543 & $2.39 \mathrm{E}-05$ & 0.000764 & Up \\
\hline hsa-miR-|8Ia-5p & 3.934233 & $2.62 \mathrm{E}-05$ & 0.000786 & Up \\
\hline hsa-miR-28-5p & 3.249402 & 4.52E-05 & 0.001064 & $U_{p}$ \\
\hline hsa-miR-3200-5p & 3.499118 & $6.03 \mathrm{E}-05$ & 0.001152 & $U_{p}$ \\
\hline hsa-miR-106b-3p & 3.17598 & $7.23 \mathrm{E}-05$ & 0.001167 & Up \\
\hline hsa-miR-130a-3p & 3.227388 & $7.73 \mathrm{E}-05$ & 0.001184 & $U_{p}$ \\
\hline hsa-miR-126-5p & 3.329919 & $7.94 \mathrm{E}-05$ & 0.00119 & Up \\
\hline hsa-miR-4762-5p & -3.29506 & 0.000158 & 0.001839 & Down \\
\hline hsa-miR-378c & $3.52584 I$ & 0.000171 & 0.00185 & Up \\
\hline hsa-miR-374a-5p & 3.48526 & 0.000189 & 0.001889 & $U_{p}$ \\
\hline hsa-miR-29c-5p & 3.161635 & 0.000221 & 0.002036 & $U_{p}$ \\
\hline hsa-miR-I 26-3p & 3.196734 & 0.000246 & 0.002164 & Up \\
\hline hsa-let-7a-5p & 3.626154 & 0.000248 & 0.002164 & Up \\
\hline hsa-miR-339-3p & 3.235942 & 0.000261 & 0.002187 & Up \\
\hline hsa-miR-30la-3p & 3.358697 & 0.000278 & 0.002292 & Up \\
\hline hsa-miR-47| I-3p & -3.28102 & 0.001108 & 0.005396 & Down \\
\hline hsa-miR-|4|-3p & 3.03568 & 0.016527 & 0.03819 & Up \\
\hline
\end{tabular}

Abbreviations: FC, fold change; FDR, false discovery rate.
Table 2 Top 20 Differentially Expressed mRNAs in Osteonecrosis of the Femoral Head

\begin{tabular}{|c|c|c|c|c|}
\hline Symbol & LogFC & $P$-value & FDR & Up/Down \\
\hline CIOorfl05 & 3.03737 & $9.90 \mathrm{E}-12$ & 2.15E-07 & $U_{p}$ \\
\hline ARL4C & 2.533696 & $2.73 \mathrm{E}-\mathrm{II}$ & $2.55 \mathrm{E}-07$ & Up \\
\hline EGR2 & $2.55 \mid 482$ & $3.52 \mathrm{E}-\mathrm{II}$ & $2.55 \mathrm{E}-07$ & $U_{p}$ \\
\hline LRRCI5 & 2.360616 & $5.3 \mid \mathrm{IE}-\mathrm{II}$ & $2.68 \mathrm{E}-07$ & $U_{p}$ \\
\hline AMTN & 3.203584 & $6.15 \mathrm{E}-11$ & $2.68 \mathrm{E}-07$ & $U_{p}$ \\
\hline ILII & 2.257176 & 7.78E-II & $2.82 \mathrm{E}-07$ & $U_{p}$ \\
\hline FAP & 2.516977 & $2.84 \mathrm{E}-10$ & 8.7IE-07 & $U_{p}$ \\
\hline VEGFC & $|.9874|$ & $3.44 \mathrm{E}-10$ & 8.7IIE-07 & $U_{p}$ \\
\hline FZDIO & 2.128076 & $3.60 \mathrm{E}-10$ & 8.7IE-07 & Up \\
\hline MMPI3 & 2.670397 & 5.32E- 10 & I.16E-06 & Up \\
\hline MSMP & -3.01757 & $1.28 \mathrm{E}-09$ & $1.74 \mathrm{E}-06$ & Down \\
\hline VIT & -1.35337 & 3.IIE-09 & $3.06 \mathrm{E}-06$ & Down \\
\hline HLA-DRB4 & -1.49327 & 3. $17 \mathrm{E}-09$ & $3.06 \mathrm{E}-06$ & Down \\
\hline RNASEI & $-|.5578|$ & $3.23 \mathrm{E}-09$ & $3.06 \mathrm{E}-06$ & Down \\
\hline RCAN2 & -1.70034 & 4.4IE-09 & $3.75 \mathrm{E}-06$ & Down \\
\hline DACTI & -1.65655 & $5.18 \mathrm{E}-09$ & $3.75 \mathrm{E}-06$ & Down \\
\hline APOD & -1.67708 & $5.18 \mathrm{E}-09$ & $3.75 \mathrm{E}-06$ & Down \\
\hline TYROBP & -1.27919 & $8.36 \mathrm{E}-09$ & $4.92 \mathrm{E}-06$ & Down \\
\hline CTSH & -1.55528 & I.03E-08 & $5.16 \mathrm{E}-06$ & Down \\
\hline HLA-DRA & -1.92425 & I.35E-08 & $5.44 \mathrm{E}-06$ & Down \\
\hline
\end{tabular}

Abbreviations: FC, fold change; FDR, false discovery rate.

1,205 edges. The top 10 differentially expressed miRNAs that targeted the most differentially expressed mRNAs were hsa-miR-378c, hsa-miR-3191-5p, hsa-let-7a-5p, hsamiR-28-5p, hsa-miR-3200-5p, hsa-miR-532-5p, hsa-miR -106b-3p, hsa-miR-339-3p, hsa-miR-5195-5p, and hsamiR-3200-3p. In addition, the sub-network of miRNAtarget mRNAs between hsa-miR-378c, hsa-let-7a-5p, hsamiR-28-5p, hsa-miR-3200-5p, hsa-miR-532-5p, and their targeted mRNAs are shown in Figure 4. In addition, we used the TargetScan (http://www.targetscan.org/vert_72/) software to further validate the targeted relationship between miRNA and mRNA, such as hsa-miR-378cDACT1 and hsa-miR-28-5p-RELA (supplementary Figure 1).

\section{Functional Analysis of Targeted mRNAs}

GO and KEGG analysis of targeted mRNAs is shown in supplementary Table 4 . The top five significant enrichment GO terms and all KEGG terms are presented in Figures 5 and 6, respectively. Total KEGG terms involving targeted differentially expressed mRNAs are shown in Table 3. In the KEGG terms, we found seven valuable signaling pathways including the Wnt signaling pathway (involved WNT3A), chemokine signaling pathway (involved RELA), focal adhesion and ECM-receptor interaction 
A Volcano plot

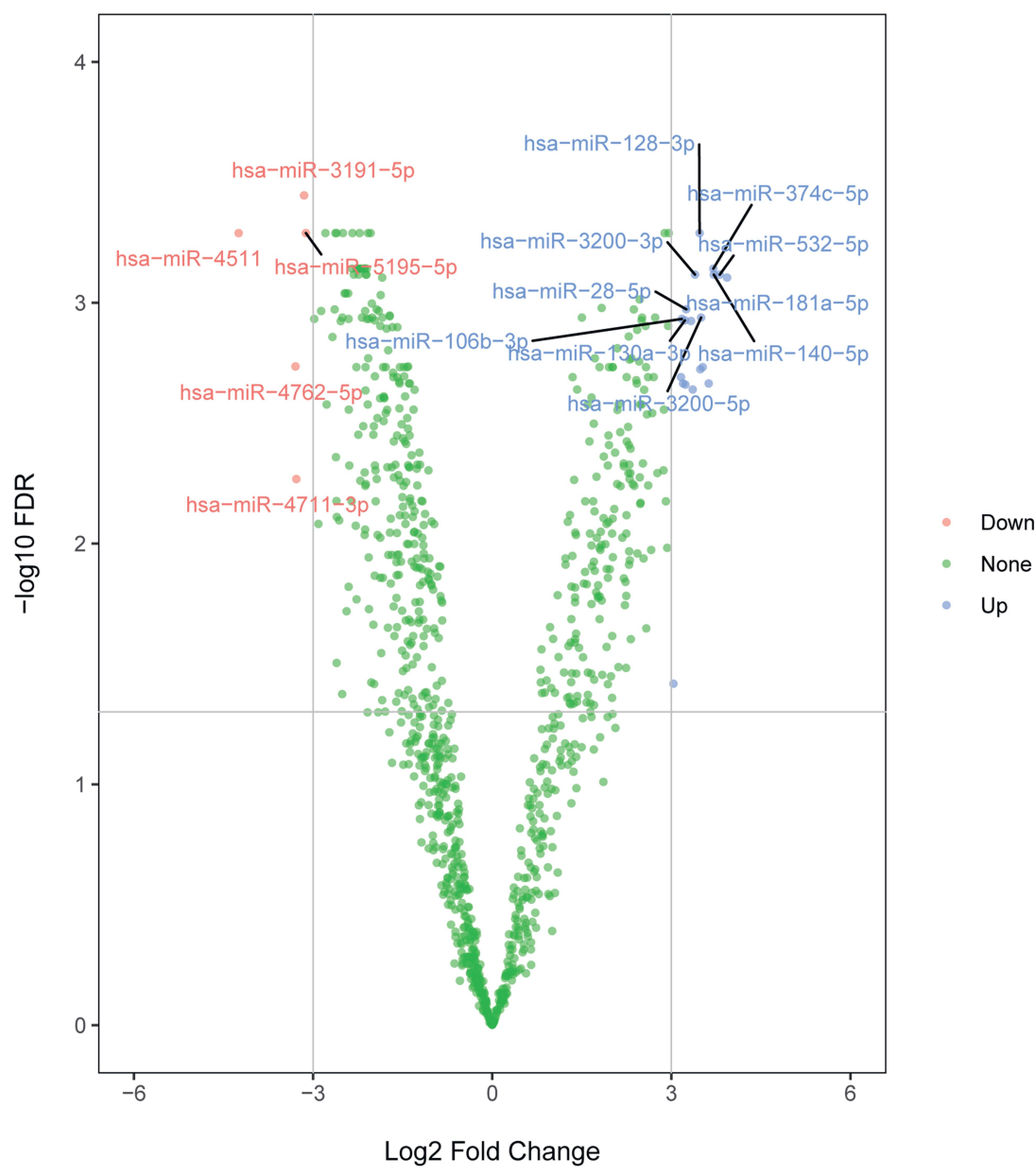

B

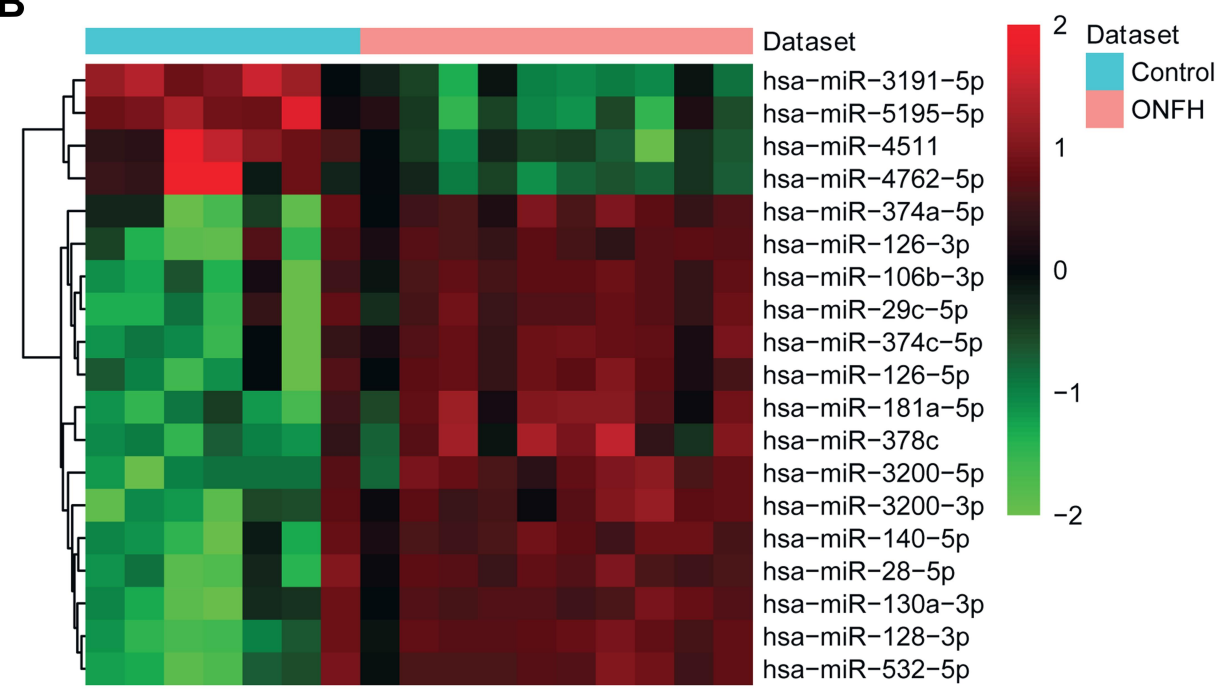

Figure I The volcano plot and heat map of all differentially expressed miRNAs in osteonecrosis of the femoral head. (A) The volcano plot of all differentially expressed miRNAs. The $X$ and $Y$ axis represents Log2 Fold Change and - $\log 10$ FDR, respectively. Blue and red represents up-regulated and down-regulated miRNAs, respectively. (B) The heat map of all differentially expressed miRNAs.

Abbreviation: ONFH, osteonecrosis of the femoral head. 


\section{A \\ Volcano plot}

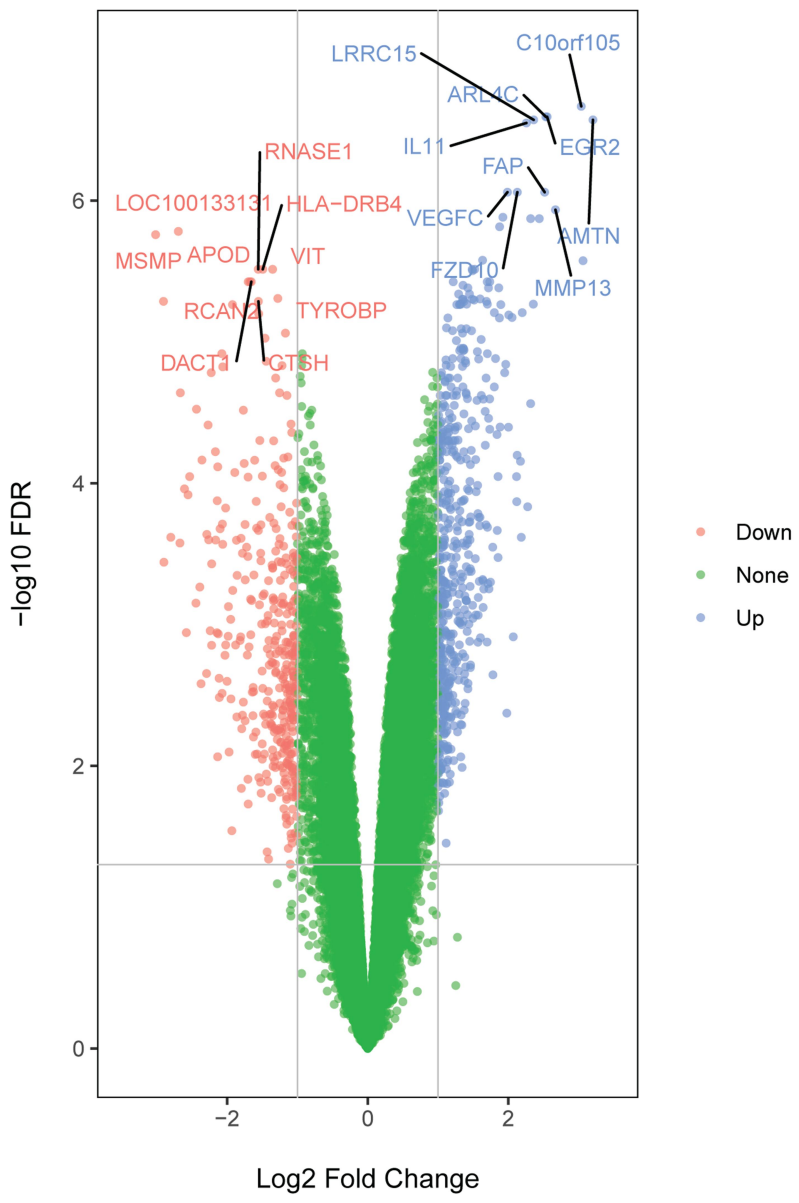

B

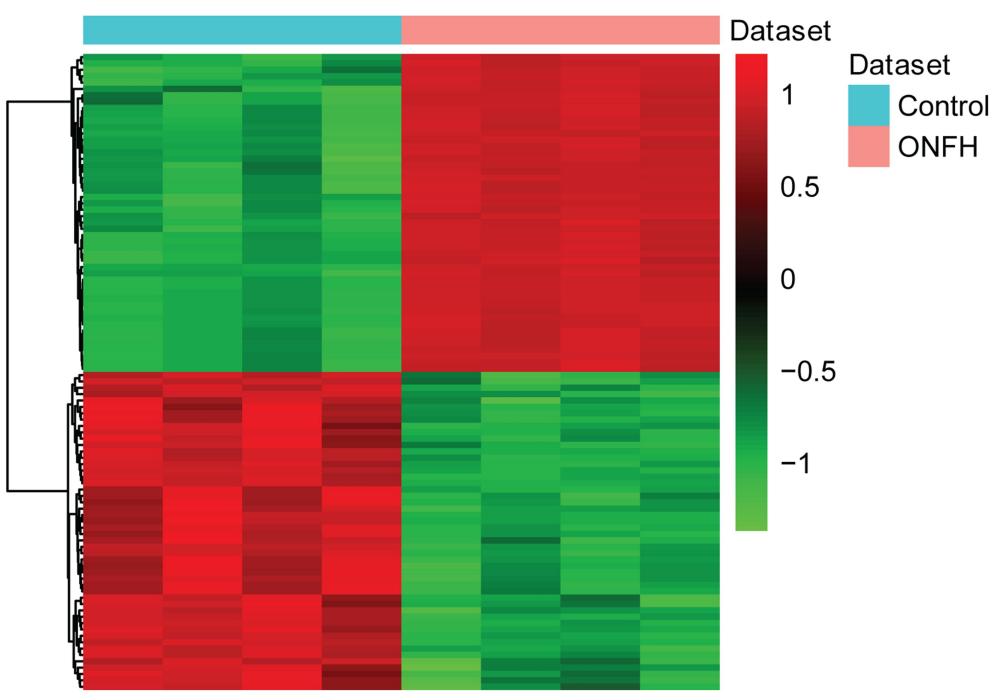

Figure 2 The volcano plot and heat map of the top 100 differentially expressed mRNAs in osteonecrosis of the femoral head. (A) The volcano plot of the top 100 differentially expressed mRNAs. The X- and Y-axes represent Log2 Fold Change and -log 10 FDR, respectively. Blue and red represent up-regulated and down-regulated mRNAs, respectively. (B) The heat map of the top 100 differentially expressed mRNAs.

Abbreviation: ONFH, osteonecrosis of the femoral head. 


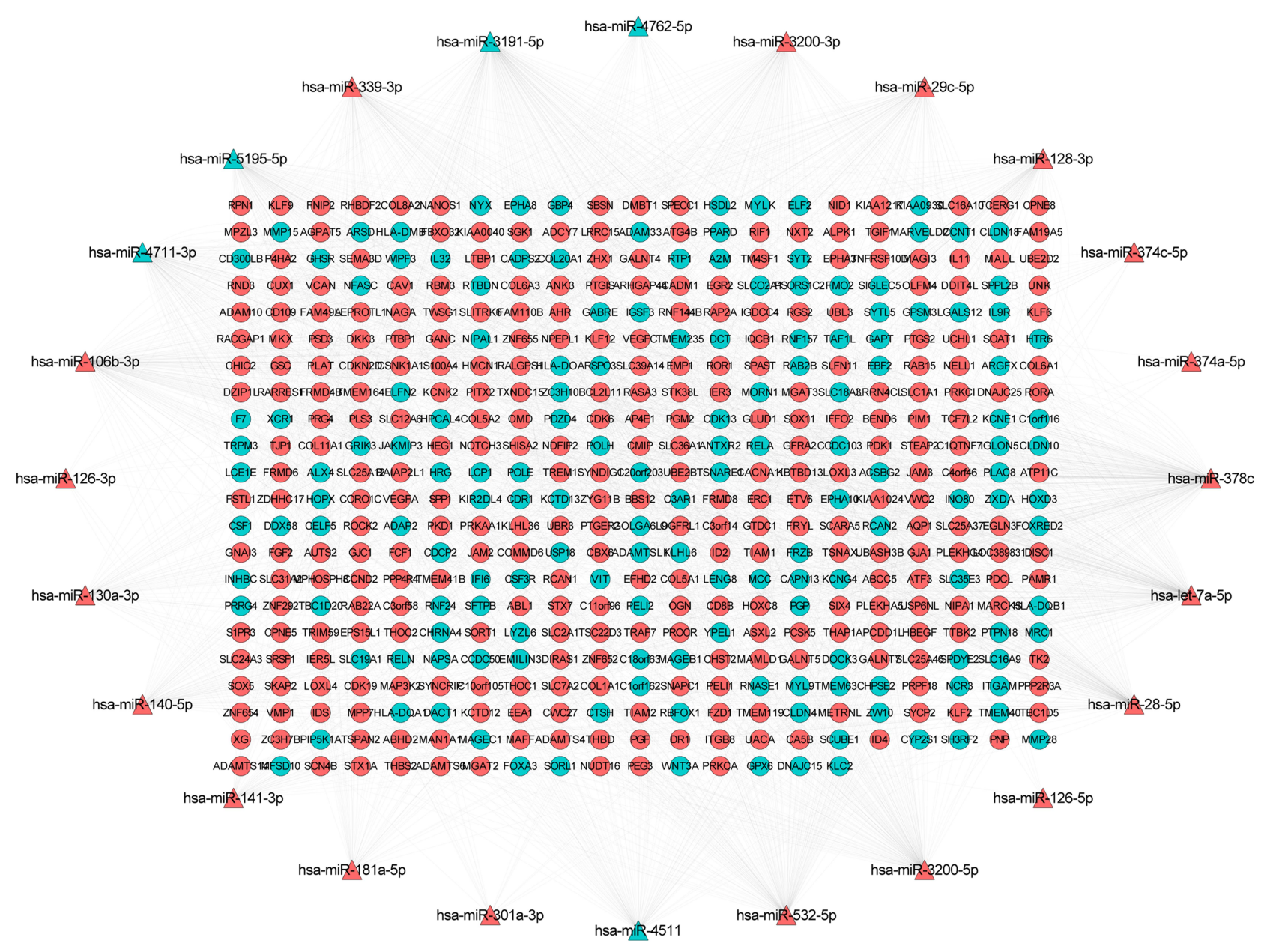

Figure 3 The network of miRNA-target mRNAs between 24 miRNAs and 457 mRNAs in osteonecrosis of the femoral head. The triangle and circule represent the differentially expressed miRNAs and targeted differentially expressed mRNAs, respectively. The red and green color represent up-regulation and down-regulation, respectively.

(involved RELN), cell adhesion molecules (CAMs) (involved CLDN18 and CLDN10), cytokine-cytokine receptor interaction, and hematopoietic cell lineage (involving CSF1 and IL9R).

\section{In vitro Validation}

Six patients with osteonecrosis of the femoral head and seven normal controls were incorporated in our study. Clinical information of these individuals is shown in Table 4. As mentioned above, hsa-miR-28-5p was one of the top 10 differentially expressed miRNAs that targeted the most differentially expressed mRNAs. WNT3A, RELA, and RELN were involved in KEGG pathways. RCAN2 was in the top 20 down-regulated mRNAs. We selected hsa-miR-28-5p, WNT3A, RCAN2, RELA, and RELN for validation (Figure 7). The relative expression of hsa-miR-28-5p was significantly up-regulated, the relative expression of WNT3A, RCAN2, RELA, and RELN was down-regulated in patients with osteonecrosis of the femoral head. The validated result was in line with the bioinformatics analysis.

\section{Expression Validation and Diagnostic Analysis of Targeted mRNAs}

The GSE123568 dataset was firstly utilized to validate the expression of CLDN10, CLDN18, CSF1, DACT1, IL9R, RCAN2, RELN, and WNT3A (Figure 8). The expression of these mRNAs was all significantly down-regulated, which is in line with the bioinformatics analysis. In addition, the ROC curve analysis was performed to assess the diagnosis ability of these mRNAs in the GSE123568 dataset (Figure 9). The AUC of these mRNAs was more than 0.7 , which suggested that they had a diagnostic value for osteonecrosis of the femoral head. 


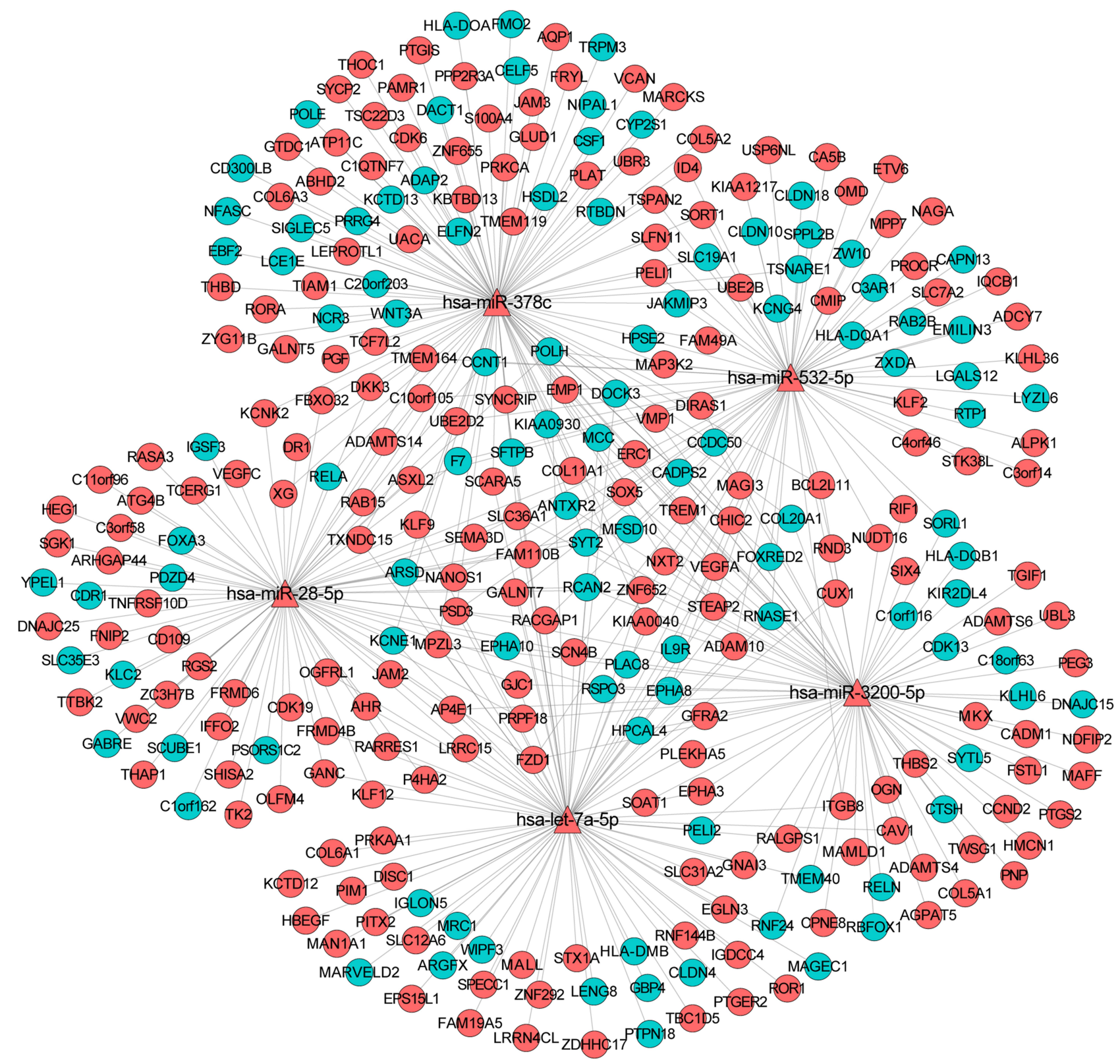

Figure 4 The sub-network of miRNA-target mRNAs between hsa-miR-378c, hsa-let-7a-5p, hsa-miR-28-5p, hsa-miR-3200-5p, hsa-miR-532-5p, and their targeted mRNAs in osteonecrosis of the femoral head. The triangle and circule represent the differentially expressed miRNAs and targeted differentially expressed mRNAs, respectively. The red and green color represent up-regulation and down-regulation, respectively.

\section{Discussion}

Hsa-miR-378c, a hypoxia-regulated miRNA, is reported to be down-regulated in rheumatoid arthritis and osteosarcomas. ${ }^{29,30}$ The level of hsa-miR-378c was increased in osteonecrosis of the femoral head in this study. Moreover, three down-regulated mRNAs including Wnt family member 3A (WNT3A), dishevelled binding antagonist of beta catenin 1 (DACT1), and colony stimulating factor 1 (CSF1) were all regulated by hsa-miR-378c. Significantly, WNT3A, DACT1, and CSF1 had a diagnostic value for osteonecrosis of the femoral head. WNT3A can induce chondrocytes proliferation and alter the extracellular matrix synthesis function of the chondrocytes. ${ }^{31}$ In addition, WNT3A and hypoxia could act together to promote angiogenesis by regulating cell death. ${ }^{32}$ It is noted that liposome-reconstituted recombinant human WNT3A protein has been used to treat osteonecrosis defect. ${ }^{33}$ The expression of DACT1 is found in primary chondrocytes and vascular endothelial cells. ${ }^{34,35}$ Käkönen and 

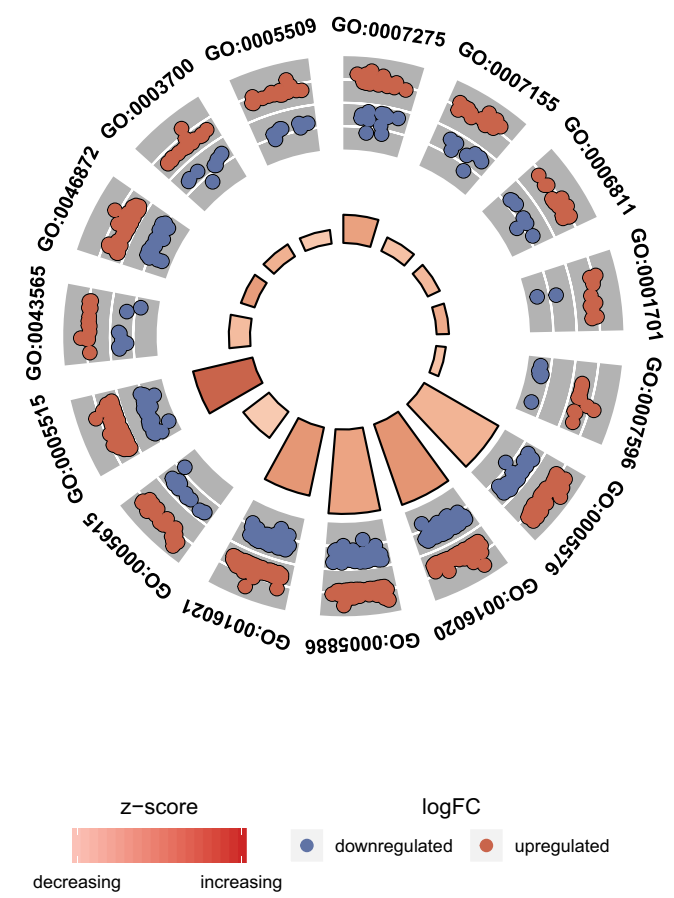

\begin{tabular}{|c|c|}
\hline ID & \begin{tabular}{c} 
Description \\
\hline GO:0007275
\end{tabular} \\
\hline GO:0007155 & multicellular organismal development (BP) \\
\hline GO:0006811 & cell adhesion (BP) \\
\hline GO:0001701 & ion transport (BP) \\
\hline GO:0007596 & in utero embryonic development (BP) \\
\hline GO:0005576 & blood coagulation (BP) \\
\hline GO:0016020 & extracellular region (CC) \\
\hline GO:0005886 & membrane (CC) \\
\hline GO:0016021 & plasma membrane (CC) \\
\hline GO:0005615 & integral to membrane (CC) \\
\hline GO:0005515 & extracellular space (CC) \\
\hline GO:0043565 & protein binding (MF) \\
\hline GO:0046872 & sequence-specific DNA binding (MF) \\
\hline GO:0003700 & sequence-specific DNA binding transcription factor activity (MF) \\
\hline GO:0005509 & metal ion binding (MF) \\
\hline
\end{tabular}

Figure 5 Top five significantly enriched GO terms of targeted differentially expressed mRNAs in osteonecrosis of the femoral head. The z-score clustering in the GO terms of targeted differentially expressed mRNA is shown below. The red and blue color represent up-regulated and down-regulated mRNA, respectively.

Abbreviations: BP, biological process; CC, cellular component; MF, molecular function; FC, fold change.

Mundy $^{36}$ found that CSF-1 could interact with osteoblast to regulate the RANK-RANKL pathway to stimulate osteoclast precursors, ultimately leading to osteolysis. Additionally, CSF1, combined with VEGF-A, induces angiogenesis and recruitment of pericyte to neovessels. ${ }^{37}$ Our result suggested that WNT3A, DACT1, and CSF1 may play roles in bone remodeling and angiogenesis under the regulation of hsamiR-378c in the process of osteonecrosis of the femoral head.

Hsa-let-7a-5p is down-regulated in osteogenic differentiation, while up-regulated during osteoclastogenesis, which indicates the role of hsa-let-7a-5p in the bone imbalance. ${ }^{38-40}$ Under mechanical tension, hsa-let-7a-5p is remarkably increased in cartilage endplate chondrocytes. $^{41}$ In this study, we found that hsa-let-7a-5p was up-regulated in osteonecrosis of the femoral head. Furthermore, a regulator of calcineurin 2 (RCAN2) and interleukin 9 receptor (IL9R) were down-regulated and targeted by hsa-let-7a-5p. It is worth mentioning that RCAN2 and IL9R could be considered as diagnostic biomarkers for osteonecrosis of the femoral head. RCAN2, an angiogenesis related gene, is transcribed activation by vascular endothelial growth factor (VEGF). ${ }^{42-45}$ The expression of RCAN2 is negatively correlated with cartilage proliferation and differentiation. ${ }^{46}$ It is reported that disruption of RCAN2 could lead to reducing bone mass, which is related to increased osteoclast function and reduced osteoblast function. ${ }^{47}$ IL9R is associated with hematopoietic cell lineage. ${ }^{48}$ Our result indicated that hsalet-7a-5p and its target (RCAN2 and IL9R) could be involved in osteonecrosis of the femoral head.

Deregulation of hsa-miR-28-5p is related to rheumatic diseases, such as axial spondyloarthritis and rheumatoid arthritis. $^{49,50}$ Herein, we first found that hsa-miR-28-5p was up-regulated in osteonecrosis of the femoral head. In addition, the down-regulated RELA proto-oncogene, NF$\mathrm{kB}$ subunit (RELA, also called p65) was one of the targets of hsa-miR-28-5p. It is reported that RELA is the most potent transcriptional factor of hypoxic induction factor 2 (HIF2) that regulates chondrocyte differentiation and cartilage degradation. ${ }^{51}$ Lacking or deletion of RELA inhibits the expression of cartilage catabolic factors such as matrix metalloproteinases 9 (MMP9), SRY-box transcription factor 9 (SOX9), nitric oxide synthase 2 (NOS2), and cyclooxygenase 2 (COX2) in chondrocytes, which results in reduced bone loss and accelerated cartilage degeneration. ${ }^{52-57}$ In addition, RELA is regarded as an angiogenesis modulating agent. ${ }^{58}$ It is suggested that RELA may be involved in cartilage degeneration of osteonecrosis of the femoral head under that regulation of hsamiR-28-5p. 


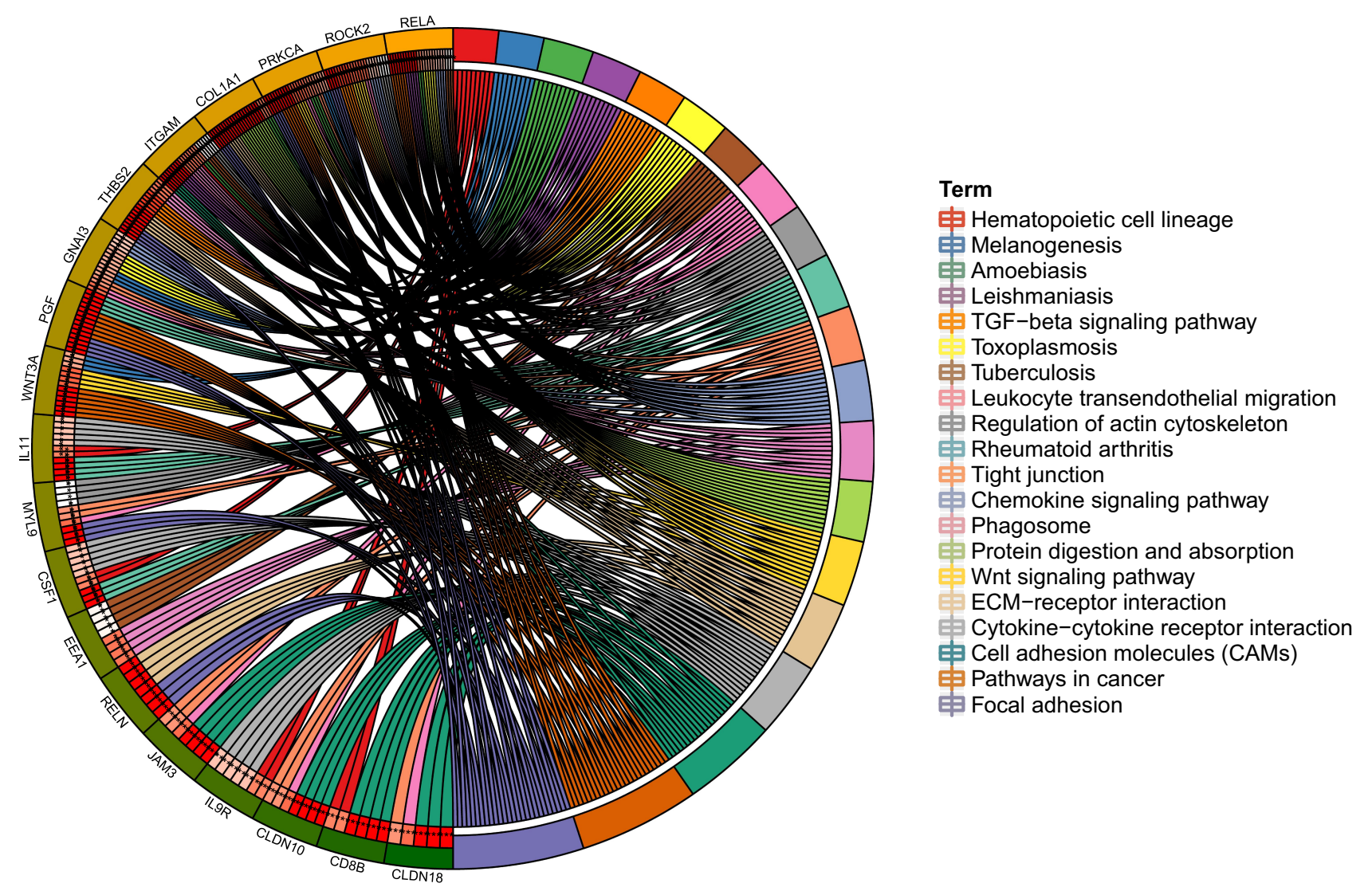

Figure 6 KEGG signaling pathways of targeted differentially expressed mRNAs in osteonecrosis of the femoral head. Different colors represent different signaling pathways; mRNA outside the circle represents the enriched one of mRNAs in the particular signaling pathway.

Previous studies on hsa-miR-3200-5p in orthopedic disease are very rare, and only a recent report showed significantly higher expression of hsa-miR-3200-5p in the osteosarcoma. ${ }^{59}$ In our study, we found that the expression level of hsa-miR-3200-5p was increased in osteonecrosis of the femoral head. Moreover, down-regulated reelin (RELN) was targeted by hsa-miR-3200-5p. It is noted that RELN had a diagnostic value for osteonecrosis of the femoral head. RELN, expressed in osteoblast lineage cells, is considered as a stromal cell-specific and hematopoietic cell-lineage marker. ${ }^{60}$ Clinically, RELN is a potential molecular target candidate for diagnosis and therapy of rheumatoid arthritis. ${ }^{61}$ Our result indicated that hsa-miR-3200-5p and RELN may play a critical role in osteonecrosis of the femoral head.

Hsa-miR-532-5p plays roles in the regulation of the adaptation to hypoxia in endothelial cells. ${ }^{62}$ Hsa-miR-532$5 \mathrm{p}$ is differentially expressed in chondrocytes from distinct regions of developing human cartilage. ${ }^{63}$ In the present study, we found that hsa-miR-532-5p was up-regulated in osteonecrosis of the femoral head. Furthermore, claudin 18 (CLDN18) and claudin 10 (CLDN10) were downregulated and regulated by hsa-miR-532-5p. In addition, CLDN18 and CLDN10 were associated with disease diagnosis. Elevated expression of CLDN18 is found in osteoblasts. ${ }^{64,65}$ Knock-out of CLDN18 leads to reduced bone mass from hyperactive osteoclasts. ${ }^{64}$ The expression of CLDN10 is increased in osteosarcoma osteoblast cells. ${ }^{66}$ Our result suggested that CLDN18 and CLDN10 could be associated with bone loss under the regulation of hsa-miR-532-5p in osteonecrosis of the femoral head.

Based on KEGG analysis, we found seven valuable signaling pathways including the Wnt signaling pathway (involved WNT3A), chemokine signaling pathway (involved RELA), focal adhesion and ECM-receptor interaction (involved RELN), cell adhesion molecules (CAMs) (involved CLDN18 and CLDN10), cytokine-cytokine receptor interaction, and hematopoietic cell lineage (involved CSF1 and IL9R) in osteonecrosis of the femoral head. The Wnt/ $\beta$-catenin pathway induces VEGF to 
Table 3 Total KEGG Terms Involved Targeted Differentially Expressed mRNAs in Osteonecrosis of the Femoral Head

\begin{tabular}{|c|c|c|c|c|}
\hline Terms & Count & P-value & FDR & mRNAs \\
\hline Focal adhesion & 19 & 2.09E-II & 3.15E-09 & $\begin{array}{l}\text { RELN,PGF,MYLK,ROCK2,CCND2,SPPI,PRKCA,COL5A2,CAVI,COLIAI, } \\
\text { THBS2,VEGFC,COL5AI,ITGB8,COL6AI,VEGFA,MYL9,COLIIAI,COL6A3 }\end{array}$ \\
\hline Pathways in cancer & 16 & 7.87E-06 & 0.00017 & $\begin{array}{l}\text { CDK6,PPARD,EGLN3,FGF2,PGF,ABLI,WNT3A,CSF3R,PRKCA,FZDI, } \\
\text { VEGFC,TCF7L2,RELA,SLC2AI,VEGFA,PTGS2 }\end{array}$ \\
\hline $\begin{array}{l}\text { Cell adhesion molecules } \\
\text { (CAMs) }\end{array}$ & 15 & $1.25 \mathrm{E}-10$ & $9.43 \mathrm{E}-09$ & $\begin{array}{l}\text { JAM3,JAM2,HLA-DOA,NFASC,ITGAM,CD8B,CADMI,HLA-DQAI, } \\
\text { CLDNI8,CLDNI0,HLA-DQBI,ITGB8,HLA-DMB,VCAN,CLDN4 }\end{array}$ \\
\hline Tight junction & 11 & I.35E-06 & 4.07E-05 & $\begin{array}{l}\text { JAM3,JAM2,TJPI,GNAI3,PRKCA,MAGI3,CLDNI8,CLDNI0,PRKCI,MYL9, } \\
\text { CLDN4 }\end{array}$ \\
\hline ECM-receptor interaction & 10 & I.70E-07 & 8.54E-06 & $\begin{array}{l}\text { RELN,SPPI,COL5A2,COLIAI,THBS2,COL5AI,ITGB8,COL6AI,COLIIAI, } \\
\text { COL6A3 }\end{array}$ \\
\hline $\begin{array}{l}\text { Leukocyte transendothelial } \\
\text { migration }\end{array}$ & 10 & 2.7IE-06 & $6.83 \mathrm{E}-05$ & $\begin{array}{l}\text { JAM3,JAM2,ROCK2,ITGAM,GNAI3,PRKCA,CLDNI8,CLDNI0,MYL9, } \\
\text { CLDN4 }\end{array}$ \\
\hline $\begin{array}{l}\text { Cytokine-cytokine receptor } \\
\text { interaction }\end{array}$ & 9 & 0.00791727 & 0.031461 & TNFRSFIOD,ILI I,INHBC,CSF3R,CSFI,XCR I,VEGFC,VEGFA,IL9R \\
\hline $\begin{array}{l}\text { Protein digestion and } \\
\text { absorption }\end{array}$ & 9 & $9.24 \mathrm{E}-07$ & 3.49E-05 & $\begin{array}{l}\text { SLC36AI,SLCIAI,COL5A2,COLIAI,COL5AI,COL6AI,COLIIAI, } \\
\text { COL6A3,SLCI6AI0 }\end{array}$ \\
\hline $\begin{array}{l}\text { Regulation of actin } \\
\text { cytoskeleton }\end{array}$ & 9 & 0.00196338 & 0.01098 & FGF2,TIAMI,MYLK,ROCK2,ITGAM,PIP5K IA,TIAM2,ITGB8,MYL9 \\
\hline Phagosome & 9 & $9.15 \mathrm{E}-05$ & 0.001256 & $\begin{array}{l}\text { HLA-DOA,ITGAM,HLA-DQAI,THBS2,STX7,EEAI,HLA-DQBI,MRCI, } \\
\text { HLA-DMB }\end{array}$ \\
\hline Tuberculosis & 8 & $0.002 \mid 4245$ & 0.011554 & HLA-DOA,ITGAM,HLA-DQAI,RELA,EEAI,HLA-DQBI,MRCI,HLA-DMB \\
\hline Wnt signaling pathway & 8 & 0.000859587 & 0.006181 & PPARD,ROCK2,CCND2,WNT3A,PRKCA,FZDI,TCF7L2,CSNKIAI \\
\hline Rheumatoid arthritis & 8 & $1.58 \mathrm{E}-05$ & 0.000299 & PGF,ILI I,HLA-DOA,CSFI,HLA-DQA I,HLA-DQBI,VEGFA,HLA-DMB \\
\hline $\begin{array}{l}\text { Chemokine signaling } \\
\text { pathway }\end{array}$ & 7 & 0.0121892 & 0.044892 & TIAMI,ROCK2,ADCY7,GNAI3,XCRI,TIAM2,RELA \\
\hline TGF-beta signaling pathway & 7 & 0.000108744 & 0.001368 & ROCK2,INHBC,PITX2,LTBPI,ID4,THBS2,ID2 \\
\hline Toxoplasmosis & 7 & 0.00128054 & 0.007734 & HLA-DOA,GNAI3,HLA-DQAI,RELA,HLA-DQBI,PDKI,HLA-DMB \\
\hline Melanogenesis & 7 & 0.000330342 & 0.003118 & WNT3A,ADCY7,GNAI3,PRKCA,FZDI,TCF7L2,DCT \\
\hline Leishmaniasis & 7 & 2.67E-05 & 0.000448 & HLA-DOA,ITGAM,HLA-DQAI,RELA,HLA-DQBI,HLA-DMB,PTGS2 \\
\hline Amoebiasis & 7 & 0.000421534 & 0.003744 & ITGAM,PRKCA,COL5A2,COLIAI,COL5AI,RELA,COLIIAI \\
\hline Hepatitis C & 6 & 0.00865149 & 0.033497 & DDX58,CLDNI8,CLDNI0,RELA,PDKI,CLDN4 \\
\hline Lysosome & 6 & 0.00552762 & 0.023848 & NAPSA,NAGA,CTSH,SORTI,AP4EI,IDS \\
\hline Axon guidance & 6 & $0.0072266 I$ & 0.029492 & EPHA8,ABLI,ROCK2,GNAI3,SEMA3D,EPHA3 \\
\hline Hematopoietic cell lineage & 6 & 0.000824081 & 0.006222 & ILI I,ITGAM,CSF3R,CSFI,CD8B,IL9R \\
\hline Gap junction & 6 & 0.00111969 & 0.007045 & TJPI,ADCY7,GNAI3,PRKCA,MAP3K2,GJAI \\
\hline $\begin{array}{l}\text { Epithelial cell signaling in } \\
\text { Helicobacter pylori } \\
\text { infection }\end{array}$ & 6 & 0.000260077 & 0.002805 & JAM3,JAM2,TJPI,ADAMI0,HBEGF,RELA \\
\hline
\end{tabular}


Table 3 (Continued).

\begin{tabular}{|c|c|c|c|c|}
\hline Terms & Count & P-value & FDR & mRNAs \\
\hline $\begin{array}{l}\text { Staphylococcus aureus } \\
\text { infection }\end{array}$ & 6 & $3.08 \mathrm{E}-05$ & 0.000466 & HLA-DOA,ITGAM,HLA-DQAI,C3ARI,HLA-DQBI,HLA-DMB \\
\hline Viral myocarditis & 6 & 0.000185105 & 0.00215 & ABLI,HLA-DOA,CAVI,HLA-DQAI,HLA-DQBI,HLA-DMB \\
\hline $\begin{array}{l}\text { Complement and } \\
\text { coagulation cascades }\end{array}$ & 5 & 0.00169723 & 0.009857 & THBD,A2M,PLAT,C3ARI,F7 \\
\hline Gastric acid secretion & 5 & 0.00266688 & 0.01299 & MYLK,ADCY7,GNAI3,PRKCA,KCNK2 \\
\hline Renal cell carcinoma & 5 & 0.00235692 & 0.011863 & EGLN3,PGF,VEGFC,SLC2AI,VEGFA \\
\hline Pancreatic cancer & 5 & 0.00235692 & 0.011863 & CDK6,PGF,VEGFC,RELA,VEGFA \\
\hline $\begin{array}{l}\text { Antigen processing and } \\
\text { presentation }\end{array}$ & 5 & 0.000864725 & 0.005935 & HLA-DOA,CD8B,HLA-DQAI,HLA-DQBI,HLA-DMB \\
\hline $\begin{array}{l}\text { Autoimmune thyroid } \\
\text { disease }\end{array}$ & 4 & 0.00292128 & 0.013367 & HLA-DOA,HLA-DQAI,HLA-DQBI,HLA-DMB \\
\hline Type I diabetes mellitus & 4 & 0.00101917 & 0.006691 & HLA-DOA,HLA-DQAI,HLA-DQBI,HLA-DMB \\
\hline $\begin{array}{l}\text { Intestinal immune network } \\
\text { for IgA production }\end{array}$ & 4 & 0.0026893 & 0.01269 & HLA-DOA,HLA-DQAI,HLA-DQBI,HLA-DMB \\
\hline N-Glycan biosynthesis & 4 & 0.00398592 & 0.017702 & RPNI,MANIAI,MGAT2,MGAT3 \\
\hline Shigellosis & 4 & 0.00867634 & 0.032753 & ABLI,ROCK2,UBE2D2,RELA \\
\hline Acute myeloid leukemia & 4 & 0.006843 & 0.028703 & PPARD,TCF7L2,RELA,PIMI \\
\hline Allograft rejection & 4 & 0.000549845 & 0.004613 & HLA-DOA,HLA-DQA I,HLA-DQBI,HLA-DMB \\
\hline Graft-versus-host disease & 4 & 0.000627861 & 0.00499 & HLA-DOA,HLA-DQAI,HLA-DQBI,HLA-DMB \\
\hline Asthma & 4 & 0.000305331 & 0.003074 & HLA-DOA,HLA-DQA I,HLA-DQBI,HLA-DMB \\
\hline
\end{tabular}

Abbreviation: FDR, false discovery rate.

promote neovascularization. ${ }^{67,68}$ In addition, the signaling pathway plays a key role in regulating chondrocyte proliferation. It is found that the $\mathrm{Wnt} / \beta$-catenin pathway is involved in the process of cartilage damage. ${ }^{69}$ It is noted that the Wnt/ $\beta$-catenin pathway is associated with the pathogenesis of early stage femoral head osteonecrosis via regulating of transcriptional regulator Myc-like (c-Myc) that affects the cell apoptosis and cell cycle. ${ }^{70}$ Chemokines are involved in angiogenesis and wound healing. It is reported that chemokines secreted from chondrocytes alter functional abilities of subchondral bone osteoblasts. ${ }^{71}$ The chemokine signaling pathway is significantly enriched in immature articular cartilage after osteonecrosis of the femoral head. ${ }^{72}$ Focal adhesion, involved in cell growth, shape, and movement, attach chondrocytes to the pericellular cartilage matrix and link to intracellular organelles. It has been shown that focal adhesion is a remarkably enriched biological pathway in the immature articular cartilage after osteonecrosis of the femoral head. ${ }^{72}$ Cell adhesion molecules, such as cadherins, selectins, and immunoglobulin superfamily proteins, are associated with angiogenesis. ${ }^{73-75}$ In addition, cell adhesion molecules play a vital role in regulating cartilage matrix turnover. ${ }^{76,77}$ ECM-receptor interaction is associated with angiogenesis, chondrogenesis, and cartilage degeneration. ${ }^{78}$ It is found that ECM-receptor interaction is significantly enriched in hip cartilage with osteonecrosis of the femoral head. ${ }^{79}$ It has been identified that cytokinecytokine receptor interaction is one of the most dramatically important pathways in osteonecrosis of the femoral head. ${ }^{72,80}$ Osteoclasts originated from hematopoietic stem cells are involved in maintaining bone integrity. Normal femoral head shows trabecular bones surrounded by bone marrow endowed with hematopoietic cells. Infiltration of 
Table 4 Clinical Information of Enrolled Individuals in vitro Validation

\begin{tabular}{|c|c|c|c|c|c|c|c|c|c|}
\hline Group & Gender & Age & Weight & Pain & Function & Malformation & Joint Activities & $\begin{array}{l}\text { Cartilage } \\
\text { Injury of Hip } \\
\text { Joint }\end{array}$ & $\begin{array}{l}\text { ARCO } \\
\text { Stage }\end{array}$ \\
\hline \multirow[t]{7}{*}{ NC } & Male & 53 & 77 & No & Good & No & Normal & No & No \\
\hline & Male & 62 & 68 & No & Good & No & Normal & No & No \\
\hline & Female & 58 & 63 & No & Good & No & Normal & No & No \\
\hline & Female & 58 & 63 & No & Good & No & Normal & No & No \\
\hline & Male & 51 & 70 & No & Good & No & Normal & No & No \\
\hline & Female & 63 & 55 & No & Good & No & Normal & No & No \\
\hline & Female & 49 & 62 & No & Good & No & Normal & No & No \\
\hline \multirow[t]{6}{*}{ Case } & Male & 50 & 80 & Yes & Limp & Shortening & $\begin{array}{l}\text { Adduction abduction limited } \\
\text { and buckling } 90^{\circ}\end{array}$ & Yes & IV \\
\hline & Male & 39 & 72 & Yes & Limp & Shortening & $\begin{array}{l}\text { Adduction abduction limited } \\
\text { and buckling } 90^{\circ}\end{array}$ & Yes & IV \\
\hline & Male & 46 & 66 & Yes & Limp & Shortening & $\begin{array}{l}\text { Adduction abduction limited } \\
\text { and buckling } 80^{\circ}\end{array}$ & Yes & IV \\
\hline & Female & 35 & 62 & Yes & Limp & Shortening & $\begin{array}{l}\text { Adduction abduction limited } \\
\text { and buckling } 90^{\circ}\end{array}$ & Yes & IV \\
\hline & Female & 58 & 67 & Yes & Limp & Shortening & $\begin{array}{l}\text { Adduction abduction limited } \\
\text { and buckling } 90^{\circ}\end{array}$ & Yes & IV \\
\hline & Male & 20 & 65 & Yes & Limp & Shortening & $\begin{array}{l}\text { Adduction abduction limited } \\
\text { and buckling } 90^{\circ}\end{array}$ & Yes & IV \\
\hline
\end{tabular}

Abbreviation: NC, normal controls.

hematopoietic cell to the ischemic area plays a significant role in regulating ischemia-induced angiogenesis. ${ }^{81}$

In conclusion, the epigenetic modifications of hsamiR-378c-WNT3A/DACT1/CSF1, hsa-let-7a-5p-RCA N2/IL9R, hsa-miR-28-5p-RELA, hsa-miR-3200-5pRELN, and hsa-miR-532-5p-CLDN18/CLDN10, and seven signaling pathways (Wnt signaling pathway, chemokine signaling pathway, focal adhesion, cell adhesion molecules (CAMs), ECM-receptor interaction, cytokine-cytokine receptor interaction, and hematopoietic cell lineage) may be involved in osteonecrosis of the femoral head. In addition, CLDN10, CLDN18, CSF1, DACT1, IL9R, RCAN2, RELN, and WNT3A had a diagnostic value for osteonecrosis of the femoral

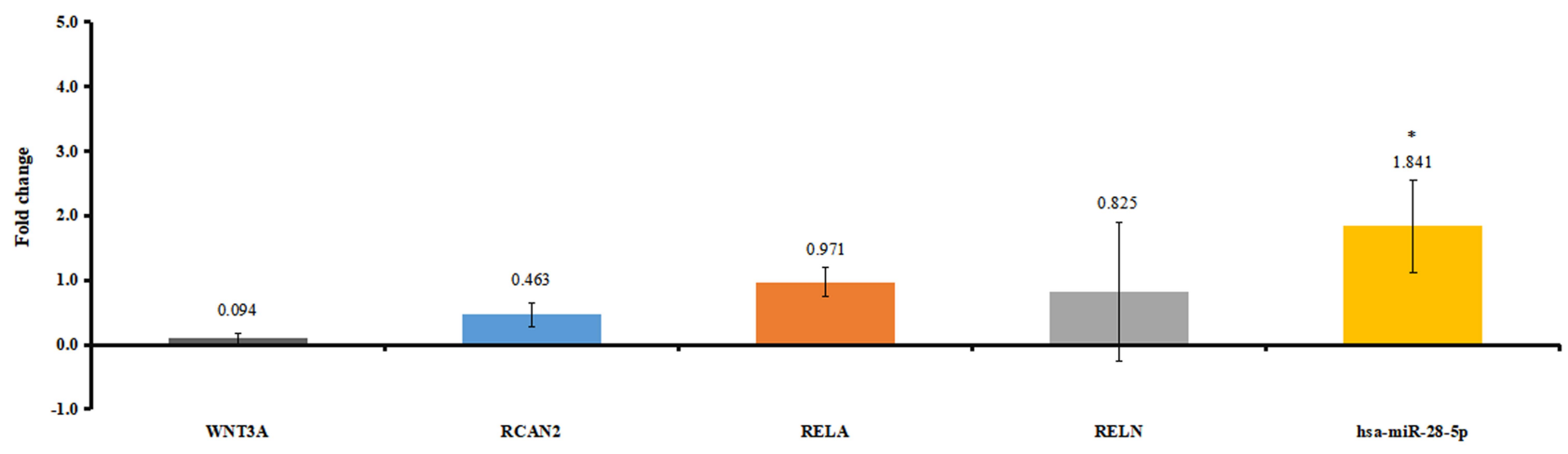

Figure 7 The in vitro validation of differentially expressed miRNAs and targeted differentially expressed mRNAs. Fold change $>$ I and fold change $<$ I represent up-regulation and down-regulation, respectively. $* P<0.05$. 


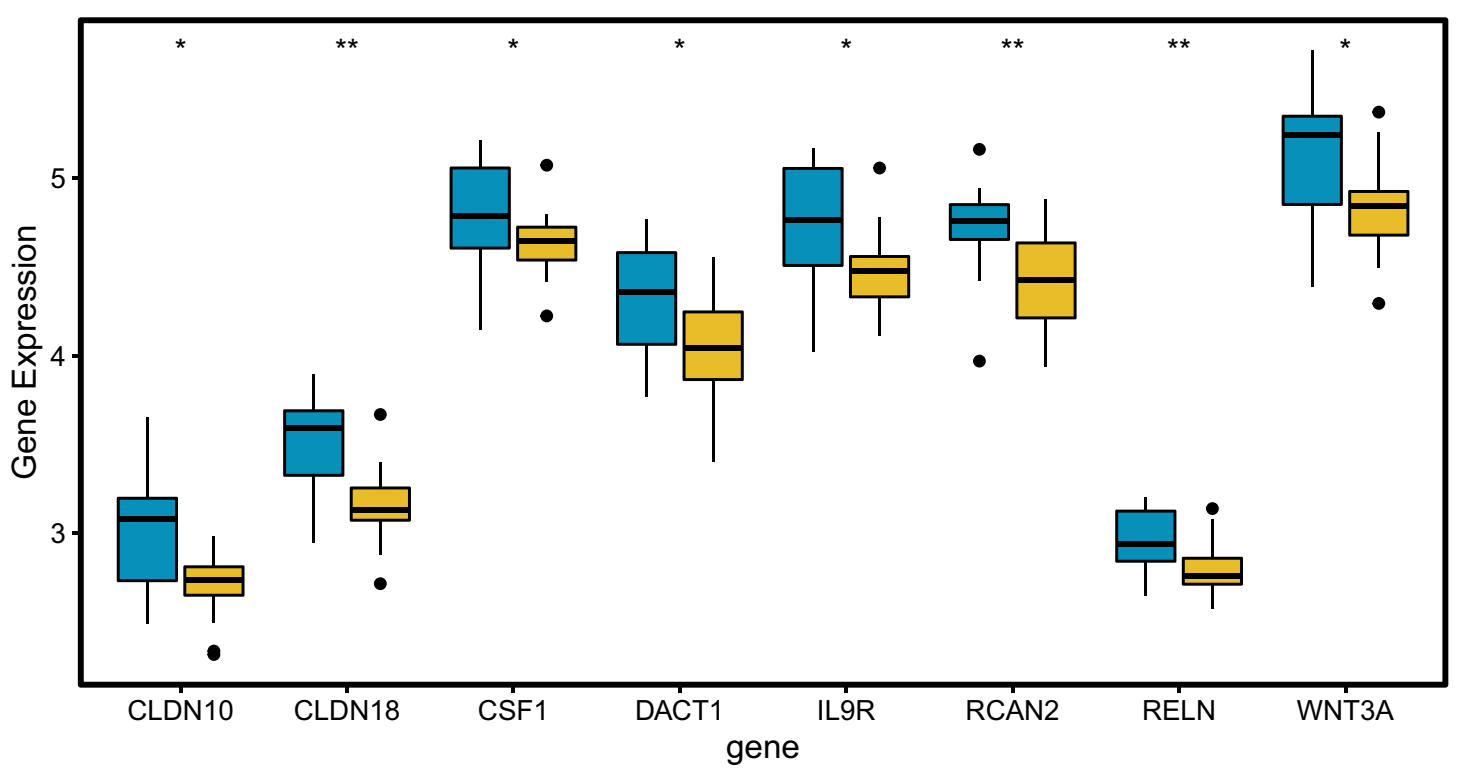

Figure 8 Expression box plots of CLDNI0, CLDNI8, CSFI, DACTI, IL9R, RCAN2, RELN, and WNT3A in the GSEI23568 dataset. $* P<0.05$, **P<0.0I. Abbreviation: ONFH, osteonecrosis of the femoral head.

head. However, there are limitations of our study. Firstly, the deeper mechanism study of identified differentially expressed miRNAs, mRNAs, and relevant downstream molecules in the disease is further needed in animal models. Secondly, the regulatory relationship between identified miRNAs and targeted mRNAs is not investigated. Further in vitro experiment, such as luciferase reporter gene assay is needed in the further study.
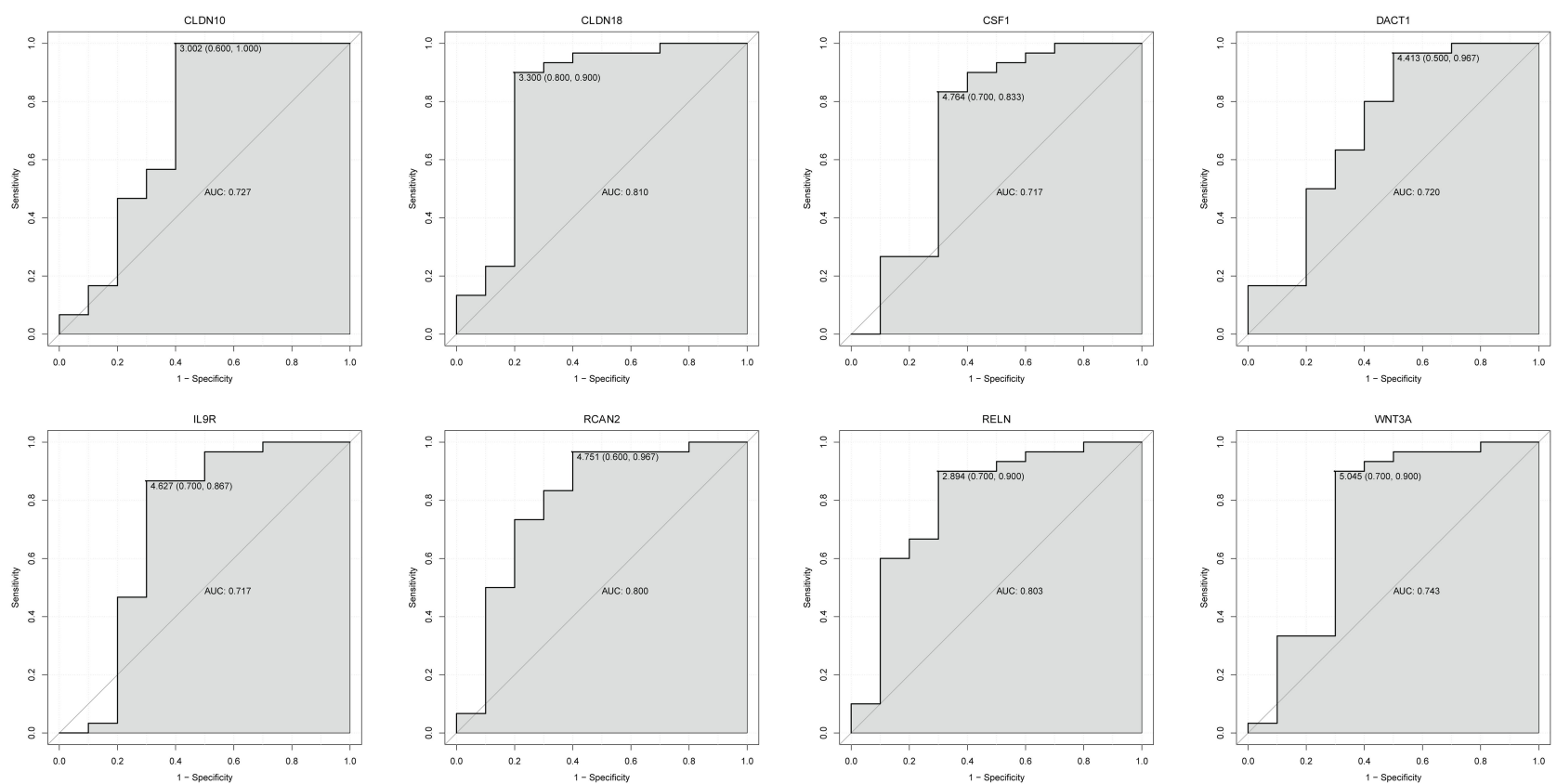

Figure 9 The ROC curves of CLDNI0, CLDNI8, CSFI, DACTI, IL9R, RCAN2, RELN, and WNT3A between osteonecrosis of the femoral head and normal controls. The ROC curves were used to show the diagnostic ability of these mRNAs with I-specificity and sensitivity. 


\section{Abbreviations}

CLDN10, claudin 10; CLDN18, claudin 18; CSF1, colony stimulating factor 1; COX2, cyclooxygenase 2; DACT1, dishevelled binding antagonist of beta catenin 1; RELN, reelin; CAMs, cell adhesion molecules; FGF2, fibroblast growth factor 2; GEO, Gene Expression Omnibus database; HIF2, hypoxic induction factor 2; IGF1, insulin-like growth factor 1; IL9R, interleukin 9 receptor; MMP9, matrix metalloproteinases 9; NOS2, nitric oxide synthase 2; RCAN2, regulator of calcineurin 2; SOX9, SRY-box transcription factor 9; VEGF, vascular endothelial growth factor; WNT3A, Wnt family member $3 \mathrm{~A}$.

\section{Acknowledgment}

This study was funded by the Department of Science and Technology of Shanxi Provincial of "The mechanism of Tongluoshenggu Decoction in the treatment of steroidinduced femoral head necrosis based on autophagy mediated by PI3K/Akt/mTOR signaling pathway" (2020SF-287).

\section{Disclosure}

No competing financial interests exist and the authors report no conflicts of interest for this work.

\section{References}

1. Aaron RK, Ciombor DM. Coagulopathies and osteonecrosis. Curr Opin Orthop. 2001;12(5):378-383. doi:10.1097/00001433200110000-00003

2. Chandler FA, Peltier LF. Coronary disease of the hip. Clin Orthop Relat Res. 2001;386:7-10. doi:10.1097/00003086-200105000-00002

3. Candinas R, Jakob M, Buckingham TA, Mattmann H, Amann FW. Vibration, acceleration, gravitation, and movement: activity controlled rate adaptive pacing during treadmill exercise testing and daily life activities. Pacing Clin Electrophysiol. 1997;20(7):1777-1786. doi:10.1111/j.1540-8159.1997.tb03566.x

4. Shah KN, Racine J, Jones LC, Aaron RK. Pathophysiology and risk factors for osteonecrosis. Curr Rev Musculoskelet Med. 2015;8:201-209. doi:10.1007/s12178-015-9277-8

5. Pouya F, Kerachian MA. Avascular necrosis of the femoral head: are any genes involved? Arch Bone Jt Surg. 2015;3:149-155.

6. Malizos KN, Karantanas AH, Varitimidis SE, Dailiana ZH, Bargiotas K, Maris T. Osteonecrosis of the femoral head: etiology, imaging and treatment. Eur J Radiol. 2007;63:0-28.

7. Zalavras CG, Lieberman JR. Osteonecrosis of the femoral head: evaluation and treatment. J Am Acad Orthop Surg. 2014;22(7):455-464. doi:10.5435/JAAOS-22-07-455

8. Mccarthy J, Puri L, Barsoum W, Lee JA, Laker M, Cooke P. Articular cartilage changes in avascular necrosis: an arthroscopic evaluation. Clin Orthop Relat Res. 2003;406:64. doi:10.1097/00003086200301000-00011

9. Magnussen RA, Guilak F, Vail TP. Articular cartilage degeneration in post-collapse osteonecrosis of the femoral head. J Bone Joint Surg Am. 2005;87:1272-1277.
10. Kerachian MA, Harvey EJ, Cournoyer D, Chow TY, Seguin C. Avascular necrosis of the femoral head: vascular hypotheses. Endothelium. 2006;13:237-244. doi:10.1080/10623320600904211

11. Huang G, Zhao G, Xia J, et al. FGF2 and FAM201A affect the development of osteonecrosis of the femoral head after femoral neck fracture. Gene. 2018;652:39-47. doi:10.1016/j.gene.20 18.01.090

12. Nobillot R, Le Parc JM, Benoit J, Paolaggi JB. Idiopathic osteonecrosis of the hip in twins. Ann Rheum Dis. 1994;53:702. doi:10.1136/ ard.53.10.702

13. Miyamoto Y, Matsuda T, Kitoh H, et al. A recurrent mutation in type II collagen gene causes Legg-Calvé-Perthes disease in a Japanese family. Hum Genet. 2007;121:625-629.

14. Chen WM, Liu Y-F, Lin M-W, et al. Autosomal dominant avascular necrosis of femoral head in two taiwanese pedigrees and linkage to chromosome 12q13. Am J Hum Genet. 2004;75:310-317. doi: $10.1086 / 422702$

15. Liu YF, Chen W-M, Lin Y-F, et al. Type II collagen gene variants and inherited osteonecrosis of the femoral head. $N$ Engl $J$ Med. 2005;352:2294-2301. doi:10.1056/NEJMoa042480

16. Larson E, Jones LC, Goodman SB, Koo KH, Cui Q. Early-stage osteonecrosis of the femoral head: where are we and where are we going in year 2018? Int Orthop. 2018;42:1-6. doi:10.1007/s00264018-3917-8

17. Arlet J. Nontraumatic avascular necrosis of the femoral head. Past Present Future. 1992;277:12-21.

18. Desforges JF, Mankin HJ. Nontraumatic necrosis of bone (Osteonecrosis). N Engl J Med. 1992;326:1473-1479. doi:10.1056/ NEJM199205283262206

19. Hamadeh IS, Ngwa BA, Gong Y. Drug induced osteonecrosis of the jaw. Cancer Treat Rev. 2015;41(5):455-464. doi:10.1016/j. ctrv.2015.04.007

20. Fang B, Li Y, Chen C, et al. Huo Xue Tong Luo capsule ameliorates osteonecrosis of femoral head through inhibiting lncRNA-Miat. J Ethnopharmacol. 2019;238:111862. doi:10.1016/j.jep.2019.111862

21. Kamiya N, Yamaguchi R, Adapala NS, et al. Legg-calve-perthes disease produces chronic hip synovitis and elevation of interleukin-6 in the synovial fluid. J Bone Miner Res. 2015;30 (6):1009-1013. doi:10.1002/jbmr.2435

22. Hyman JE, Trupia EP, Wright ML, et al. Interobserver and intraobserver reliability of the modified Waldenstrom classification system for staging of Legg-Calve-Perthes disease. J Bone Joint Surg Am. 2015;97:643-650. doi:10.2106/JBJS.N.00887

23. Eskildsen T, Taipaleenmäki H, Stenvang J, Abdallah M. Basem, Ditzel and Nicholas, MicroRNA-138 regulates osteogenic differentiation of human stromal (mesenchymal) stem cells in vivo. Proc Natl Acad Sci. 2011;108:6139-6144. doi:10.1073/pnas.1016758108

24. Itoh T, Nozawa Y, Akao Y. MicroRNA-141 and -200a are involved in bone morphogenetic protein-2-induced mouse pre-osteoblast differentiation by targeting distal-less homeobox 5. J Biol Chem. 2009;284(29):19272-19279. doi:10.1074/jbc.M109.014001

25. Huang J, Zhao L, Xing L, et al. MicroRNA-204 regulates Runx2 protein expression and mesenchymal progenitor cell differentiation. Stem Cells (Dayton, Ohio). 2010;28(2):357-364. doi:10.1002/ stem. 288

26. Kuang W, Zheng L, Xu X, et al. Dysregulation of the miR-146aSmad4 axis impairs osteogenesis of bone mesenchymal stem cells under inflammation. Bone Res. 2017;5(1):1-9. doi:10.1038/ boneres.2017.37

27. Reiner-Benaim A. FDR control by the BH procedure for two-sided correlated tests with implications to gene expression data analysis. Biom J. 2007;49:107-126. doi:10.1002/bimj.200510313

28. Benjamini Y, Hochberg Y. Controlling the false discovery rate: a practical and powerful approach to multiple testing. $J$ R Stat Soc. 1995;57:289-300. 
29. Chen Y-J, Chang W-A, Hsu Y-L, Chen C, Kuo P-L. Deduction of novel genes potentially involved in osteoblasts of rheumatoid arthritis using next-generation sequencing and bioinformatic approaches. Int J Mol Sci. 2017;18(11):2396. doi:10.3390/ijms18112396

30. Zhao H, Li M, Lihua L, et al. MiR-133b is down-regulated in human osteosarcoma and inhibits osteosarcoma cells proliferation, migration and invasion, and promotes apoptosis. PLoS One. 2013;8(12): e83571. doi:10.1371/journal.pone.0083571

31. Nalesso G, Sherwood J, Bertrand J, et al. WNT-3A modulates articular chondrocyte phenotype by activating both canonical and noncanonical pathways. J Cell Biol. 2011;193:551-564. doi:10.1083/ jcb.201011051

32. Fustermatanzo A, Manferrari G, Marchetti B, Pluchino S. Wnt3a promotes pro-angiogenic features in macrophages in vitro: implications for stroke pathology. Exp Biol Med. 2018;243:22-28.

33. Salmon B, Liu B, Shen E, et al. WNT-activated bone grafts repair osteonecrotic lesions in aged animals. Sci Rep. 2017;7(1):14254 doi:10.1038/s41598-017-14395-9

34. James CG, Ulici V, Tuckermann J, Underhill TM, Beier F. Expression profiling of Dexamethasone-treated primary chondrocytes identifies targets of glucocorticoid signalling in endochondral bone development. BMC Genom. 2007;8:205.

35. Lee YW, Eum SY, Chen KC, Hennig B, Toborek M. Gene expression profile in interleukin-4-stimulated human vascular endothelial cells. Mol Med. 2004;10:19-27.

36. Käkönen SM, Mundy GR. Mechanisms of osteolytic bone metastases in breast carcinoma. Cancer. 2003;97:834-839. doi:10.1002/ cncr.11132

37. Hsu C-W, Poché RA, Saik JE, et al. Improved angiogenesis in response to localized delivery of macrophage-recruiting molecules. PLoS One. 2015;10:e131643. doi:10.1371/journal.pone.0131643

38. Zhang J, Yu X, Yu Y, et al. MicroRNA expression analysis during FK506-induced osteogenic differentiation in rat bone marrow stromal cells. Mol Med Rep. 2017;16:581-590. doi:10.3892/mmr.2017.6655

39. Sugatani T, Vacher J, Hruska KA. A microRNA expression signature of osteoclastogenesis. Blood. 2011;117:3648-3657. doi:10.1182/ blood-2010-10-311415

40. Kagiya T, Nakamura S. Expression profiling of microRNAs in RAW264.7 cells treated with a combination of tumor necrosis factor alpha and RANKL during osteoclast differentiation. $J$ Periodontal Res. 2013;48:373-385. doi:10.1111/jre.12017

41. Feng C, Liu M, Fan X, Yang M, Zhou Y. Intermittent cyclic mechanical tension altered the microRNA expression profile of human cartilage endplate chondrocytes. Mol Med Rep. 2018;17.

42. Wang S, Li X, Parra M, Verdin E, Bassel-Duby R, Olson EN. Control of endothelial cell proliferation and migration by VEGF signaling to histone deacetylase 7. Proc Natl Acad Sci $U$ S A. 2008;105:7738-7743. doi:10.1073/pnas.0802857105

43. Ginnan R, Sun LY, Schwarz JJ, Singer HA. MEF2 is regulated by CaMKIIdelta2 and a HDAC4-HDAC5 heterodimer in vascular smooth muscle cells. Biochem J. 2012;444:105-114. doi:10.1042/ BJ20120152

44. Qin L, Zhao D, Liu X, et al. Down syndrome candidate region 1 isoform 1 mediates angiogenesis through the calcineurin-NFAT pathway. Mol Cancer Res. 2006;4:811-820. doi:10.1158/1541-7786. MCR-06-0126

45. Zeng H, Qin L, Zhao D, et al. Orphan nuclear receptor TR3/Nur77 regulates VEGF-A-induced angiogenesis through its transcriptional activity. J Exp Med. 2006;203:719-729. doi:10.1084/jem.20051523

46. Katsunori S, Naosuke K, Shunsuke T, et al. Quality evaluation of human bone marrow mesenchymal stem cells for cartilage repair. Stem Cells Int. 2017;1-9.

47. Kim JH, Kim K, Kim I, et al. RCANs regulate the convergent roles of NFATc1 in bone homeostasis. Sci Rep. 2016;6:38526. doi:10.1038/ srep38526
48. Luo D, Fan X, Ma C, et al. A study on the effect of neurogenesis and regulation of GSK3beta/PP2A expression in acupuncture treatment of neural functional damage caused by focal ischemia in MCAO rats. Evid Based Complement Alternat Med. 2014;2014:962343. doi:10.1155/2014/962343

49. Fogel O, Bugge Tinggaard A, Fagny M, et al. Deregulation of microRNA expression in monocytes and $\mathrm{CD} 4+\mathrm{T}$ lymphocytes from patients with axial spondyloarthritis. Arthritis Res Ther. 2019;21:51.

50. Maeda Y, Farina NH, Matzelle MM, et al. Synovium-derived microRNAs regulate bone pathways in rheumatoid arthritis. $J$ Bone Miner Res. 2017;32:461-472. doi:10.1002/jbmr.3005

51. Saito T, Fukai A, Mabuchi A, et al. Transcriptional regulation of endochondral ossification by HIF-2 $\alpha$ during skeletal growth and osteoarthritis development. Nat Med. 2010;16:678-686.

52. Vaira S, Johnson T, Hirbe AC, et al. RelB is the NF-Î'B subunit downstream of NIK responsible for osteoclast differentiation. Proc Nat Acad Sci USA. 2008;105:3897-3902. doi:10.1073/pnas.0708576105

53. Vaira S, Alhawagri M, Anwisye I, Kitaura H, Faccio R, Novack DV. RelA/p65 promotes osteoclast differentiation by blocking a RANKL-induced apoptotic JNK pathway in mice. J Clin Invest. 2008; 118:2088.

54. Clohisy JC, Yamanaka Y, Faccio R, Abu-Amer Y. Inhibition of IKK activation, through sequestering NEMO, blocks PMMA-induced osteoclastogenesis and calvarial inflammatory osteolysis. J Orthop Res. 2006;24(7):1358-1365. doi:10.1002/jor.20184

55. Kobayashi H, Chang SH, Mori D, et al. Biphasic regulation of chondrocytes by Rela through induction of anti-apoptotic and catabolic target genes. Nat Commun. 2016;7(1):13336. doi:10.1038/ ncomms 13336

56. Caron MM, Emans PJ, Surtel DA, et al. Activation of NF-kB/p65 facilitates early chondrogenic differentiation during endochondral ossification. PLoS One. 2012;7:e33467. doi:10.1371/journal. pone. 0033467

57. Lianxu C, Hongti J, Changlong Y. NF- $\kappa B p 65$-specific siRNA inhibits expression of genes of COX-2, NOS-2 and MMP-9 in rat IL-1 $\beta$ induced and TNF- $\alpha$-induced chondrocytes. Osteoarthr Cartil. 2006;14:367-376. doi:10.1016/j.joca.2005.10.009

58. Knudsen AR, Kannerup AS, Dich R, et al. Expression of genes involved in rat liver angiogenesis after ischaemia and reperfusion: effects of ischaemic pre- and post-conditioning. $H P B$. 2010;12:554-560. doi:10.1111/j.1477-2574.2010.00215.x

59. Li G, Li L, Qi S, Wu J, Ming C. MicroRNA-3200-5p promotes osteosarcoma cell invasion via suppression of BRMS1. Mol Cells. 2018;41:523-531.

60. Berendam SJ, Koeppel AF, Godfrey NR, et al. Comparative transcriptomic analysis identifies a range of immunologically related functional elaborations of lymph node associated lymphatic and blood endothelial cells. Front Immunol. 2019;10:816. doi:10.3389/fimmu.2019.00816

61. You S, Cho C, Lee I, et al. A systems approach to rheumatoid arthritis. PLoS One. 2012;7(12):e51508. doi:10.1371/journal. pone. 0051508

62. Kochan-Jamrozy K, Króliczewski J, Moszyńska A, et al. miRNA networks modulate human endothelial cell adaptation to cyclic hypoxia. Cell Signal. 2019;54:150-160. doi:10.1016/j. cellsig.2018.11.020

63. Audrey MA, Nobish V, Louisa W, et al. Differentially expressed microRNAs in chondrocytes from distinct regions of developing human cartilage. PLoS One. 2013;8:e75012.

64. Linares GR, Brommage R, Powell DR, et al. Claudin 18 is a novel negative regulator of bone resorption and osteoclast differentiation. J Bone Miner Res. 2012;27:1553-1565.

65. Wongdee K, Pandaranandaka J, Teerapornpuntakit J, et al. Osteoblasts express claudins and tight junction-associated proteins. Histochem Cell Biol. 2008;130:79-90. doi:10.1007/s00418-0080419-6 
66. Zhang X, Wang X, Wang A, et al. CLDN10 promotes a malignant phenotype of osteosarcoma cells via JAK1/Stat1 signaling. J Cell Commun Signal. 2019;13(3):395-405. doi:10.1007/s12079-01900509-7

67. Carsten S, Henrike M, Edward R, Ann B, Thomas F, Kenneth W. Glycogen-Synthase Kinase3beta/beta-catenin axis promotes angiogenesis through activation of vascular endothelial growth factor signaling in endothelial cells. Circ Res. 2005;96:308-318.

68. Kaga S, Zhan L, Altaf E, Maulik N. Glycogen synthase kinase-3 $\beta / \beta$ catenin promotes angiogenic and anti-apoptotic signaling through the induction of VEGF, Bcl-2 and survivin expression in rat ischemic preconditioned myocardium. J Mol Cell Cardiol. 2006;40 (1):138-147. doi:10.1016/j.yjmcc.2005.09.009

69. de Sousa Rabelo F, da Mota LM, Lima RA, et al. The Wnt signaling pathway and rheumatoid arthritis. Autoimmun Rev. 2010;9:207-210. doi:10.1016/j.autrev.2009.08.003

70. Zhang C, Zou YL, Ma J, Dang XQ, Wang KZ. Apoptosis associated with Wnt/ $\beta$-catenin pathway leads to steroid-induced avascular necrosis of femoral head. BMC Musculoskelet Disord. 2015;16. doi:10.1186/s12891-015-0606-2

71. Sharma AR, Jagga S, Lee SS, Nam JS. Interplay between cartilage and subchondral bone contributing to pathogenesis of osteoarthritis. Int J Mol Sci. 2013;14:19805-19830. doi:10.3390/ijms141019805

72. Adapala NS, Kim HKW. Comprehensive genome-wide transcriptomic analysis of immature articular cartilage following ischemic osteonecrosis of the femoral head in piglets. PloS one. 2016;11: e0153174.

73. Bach TL, Barsigian C, Chalupowicz DG, et al. VE-cadherin mediates endothelial cell capillary tube formation in fibrin and collagen gels1. Exp Cell Res. 1998;238:324-334. doi:10.1006/excr.1997.3844
74. Barreiro O, Yanez-Mo M, Serrador JM, et al. Dynamic interaction of VCAM-1 and ICAM-1 with moesin and ezrin in a novel endothelial docking structure for adherent leukocytes. $J$ Cell Biol. 2002;157:1233-1245. doi:10.1083/jcb.200112126

75. Bazzoni G. The JAM family of junctional adhesion molecules. Curr Opin Cell Biol. 2003;15:525-530. doi:10.1016/S0955-0674(03) 00104-2

76. Huang D. Extracellular matrix-cell interactions and chondrogenesis. Clin Orthop Relat Res. 1977;123:169-176.

77. Arner EC, Tortorella MD. Signal transduction through chondrocyte integrin receptors induces matrix metalloproteinase synthesis and synergizes with interleukin-1. Arthritis Rheum. 1995;38:1304-1314. doi:10.1002/art.1780380919

78. Hou C, Zhang Z, Zhang Z, et al. Presence and function of microRNA-92a in chondrogenic ATDC5 and adipose-derived mesenchymal stem cells. Mol Med Rep. 2015;12:4877-4889.

79. Zhe L, Lin Y. Identification of potential crucial genes associated with steroid-induced necrosis of femoral head based on gene expression profile. Gene. 2017;627:322. doi:10.1016/j.gene.2017.05.026

80. Yuan C, Cai J. Time-series expression profile analysis of fracture healing in young and old mice. Mol Med Rep. 2017;16:4529-4536.

81. Klotzsche-von Ameln A, Cremer S, Hoffmann J, et al. Endogenous developmental endothelial locus-1 limits ischemia-related angiogenesis by blocking inflammation. Thromb Haemost. 2017;117(6):1150. doi:10.1160/TH16-05-0354
Clinical Interventions in Aging

\section{Publish your work in this journal}

Clinical Interventions in Aging is an international, peer-reviewed journal focusing on evidence-based reports on the value or lack thereof of treatments intended to prevent or delay the onset of maladaptive correlates of aging in human beings. This journal is indexed on PubMed Central, MedLine, CAS, Scopus and the Elsevier

\section{Dovepress}

Bibliographic databases. The manuscript management system is completely online and includes a very quick and fair peer-review system, which is all easy to use. Visit http://www.dovepress.com/ testimonials.php to read real quotes from published authors. 